ZHIZHOU WU, Ph.D ${ }^{1}$.

E-mail:wuzhizhou@tongji.edu.cn

XIN ZENG, Master Degree Candidate ${ }^{1}$

E-mail: zengxin13579@qq.com

LING WANG, Ph.D. ${ }^{1}$

(Corresponding author)

E-mail: wang_ling@tongji.edu.cn

${ }^{1}$ The Key Laboratory of Road and Traffic Engineering,

Ministry of Education, Tongji University

Cao'an Road \#4800, Jiading District, Shanghai, 201804,

China

\title{
A NEW TRAFFIC CONFLICT MEASURE FOR ELECTRIC BICYCLES AT INTERSECTIONS
}

\section{ABSTRACT}

As electric bicycles (e-bikes) are becoming popular in China, concerns have been raised about their safety conditions. A traffic conflict technique is commonly used in traffic safety analysis, and there are many conflict measures designed for cars. However, e-bikes have high flexibility to change speed and trajectories, which is different from cars, so the conflict measures defined for e-bikes need to be independently explored. Based on e-bike driving characteristics, this paper proposes a new measure, the Integrated Conflict Intensity (ICI), for traffic conflicts involving e-bikes at intersections. It measures the degree of dangerousness of a conflict process, with consideration of both conflict risk and conflict severity. Time to collision is used to measure the conflict risk. Relative kinetic energy is used to measure the conflict severity. ICI can be calculated based on video analysis. The method of determining ICI thresholds for three conflict levels (serious, less serious, and slight) and two conflict types (conflicts between two e-bikes, and conflicts between an e-bike and a car) is put forward based on the questionnaires about safety perception of e-bike riders, which is regarded as the criterion of e-bike safety conditions at intersections. The video recording and a questionnaire survey about conflicts involving e-bikes at intersections have been conducted, and the unified thresholds applicable to different intersections have been determined. It is verified that ICI and its thresholds meet the criterion of e-bike safety conditions. This work is expected to be used in the selection of intersections for safety improvement of e-bike traffic.

\section{KEY WORDS}

electric bicycle; traffic conflict; conflict measure; time to collision; kinetic energy; threshold;

\section{INTRODUCTION}

In China, electric bicycles (e-bikes) have become a popular travel mode for citizens. They are as convenient and flexible as conventional bicycles, but can reach much higher speeds $(30 \mathrm{~km} / \mathrm{h}$ or even higher) [1]. According to the China Traffic Management Bureau, the number of e-bikes was 250 million in 2017. Meanwhile, from 2013 to 2017, e-bike related crashes have resulted in about 56,200 injuries and 8,431 fatalities in China. The traffic safety of e-bikes cannot be ignored.

In order to assess the safety of e-bikes when passing through intersections, there is need to propose e-bike traffic conflict technique which has been commonly used for cars. Traffic conflict was defined for the first time by Perkins \& Harris [2] as a surrogate safety measure for crashes at intersections. Baker [3] described traffic conflict as the situation in which a driver tries to avoid a potential accident or a situation of danger through the application of an evasive manoeuver (braking, lane change, or acceleration).

After decades of development, the traffic conflict technique is becoming more mature and sophisticated. However, since cars account for the majority of traffic structure in the cities, most of the research focuses on conflict measures for cars. In terms of e-bikes, the driving characteristics are different from cars, so it is inappropriate to directly apply the methods for cars to e-bikes. It is necessary to form an improved new safety measure for e-bikes based on a traffic conflict technique. 
Due to the lack of physical protection, provided by cars, e-bike riders are directly exposed to safety risks at intersections, and they take direct damage from an accident. Therefore, in terms of e-bike-related conflicts, both risk and severity are important factors. In this study, the conflict risk and the conflict severity are considered together in the proposed measure for e-bikes.

The remainder of this paper is organized as follows. Section 2 reviews the previous studies of traffic conflict measures. Section 3 discusses the driving characteristics of e-bikes. Section 4 describes the methodology. Section 5 applies and verifies the proposed measure. Finally, Section 6 summarizes the findings of this study and provides suggestions for future research.

\section{LITERATURE REVIEW}

Current studies on e-bike safety are mainly about the speed or crash characteristics based on the sample data analysis. For example, Lin et al. [4] got the operating speed and its distribution of e-bikes in China, Schepers et al. [5] compared crash severity of e-bikes with classic bicycles in the Netherlands, Gorenflo et al. [6] revealed participants' safety concerns about the speed of e-bikes in Canada, and Hertach et al. [7] analysed crash causes of e-bikes in Switzerland. Traffic conflicts related to e-bikes are rarely studied, and the only few studies are about conflict types and regions at intersections [8], without referring to safety measures.

As for current traffic conflict measures, although they are not specially designed for e-bikes, the basic methods and ideas can be of advantage. In general, the conflict measures can be divided into five categories: based on time, based on distance, based on speed, based on kinetic energy, and based on combined indicators.

1) Measures based on time

The most widely used conflict measure based on time is Time-To-Collision (TTC). The original definition of TTC proposed by Hayward [9] is the time required for two vehicles to crash if they continue moving at their current speeds and in the same direction. Obviously, TTC is a "crash-estimated" time that has not actually happened yet, and for every moment there is a corresponding TTC as long as two vehicles are in conflict. So, there may be numerous TTCs in a complete conflict process.
To assess the conflict levels, the criteria of TTC should be determined. A TTC-threshold of $1 \mathrm{~s}$ was originally formulated by Hayward [9] in order to distinguish between the so-called "near-misses" and safe driving situations. Hydén \& Linderholm [10] proposed a comparable threshold of $1.5 \mathrm{~s}$. Higher thresholds have been put forward by other researchers to suit different situations. For example, Hirst \& Graham [11] regarded a TTC measure of $4 \mathrm{~s}$ as the safe-critical value considering the driver's perception. These studies make TTC easy to use in traffic conflict analysis.

Another popular indicator is Post-Encroachment Time (PET), initially introduced by Allen et al. [12]. PET is defined as the time between the moment when the first road user leaves the path of the second road user and the moment when the second user reaches the path of the first user (i.e. PET indicates the extent to which they miss each other). PET is a period of time that has already elapsed in reality, and there is only one PET for a single conflict process.

Besides, some improved indicators based on time are put forward to extend usability, such as TA (Time-To-Accident) proposed by Hydén [13], TET (Time Exposed Time-to-Collision) and TIT (Time Integrated Time-to-Collision) proposed by Minderhoud \& Bovy [14], RTTC (Relative Time to Collision) proposed by Chen et al. [15]. But in general, TTC and PET are the most commonly used measures for the conflict analysis at intersections.

2) Measures based on distance

This kind of measures considers the distance related to conflict, such as the remaining distance to potential point of collision introduced by Allen et al. [12]. Its implication and effect are similar to the measures based on time, so it is not commonly used and discussed.

3) Measures based on speed

TTC and PET reflect the possibility of crashes, but sometimes the crash severity (once it happens) is taken into consideration rather than the crash probability. Kloeden et al. [16] found that the vehicle speed when a crash occurs, significantly contributes to the severity of that crash. Shelby [17] regarded the change in vehicle speed because of collision as a measure of traffic conflict severity. These studies take speed into consideration for its high correlation with fatal accidents.

4) Measures based on kinetic energy

It is commonly thought that at the same speed, heavier vehicles may contribute to higher crash severity. Kinetic energy combines mass with speed, 
and it indicates the potential energy of a moving vehicle, which may be released in a crash. Therefore, recent studies evaluate crash severity in the viewpoint of kinetic energy. Chen et al. [18] defined kinetic energy of conflict as the sum of the kinetic energy of conflict entities. Sobhani et al. [19] considered the change of kinetic energy using kinetic equations in physics. It is believed that kinetic energy measures crash injury severity well.

5) Measures based on combined indicators

Moreover, some studies combine two or more indicators together, making the analysis more comprehensive. For example, Fazekas et al. [20] defined DRAC (Deceleration Rate to Avoid a Crash) which is a combination of speed difference with distance. Alhajyaseen [21] proposed CI (Conflict Index) which is a combination of PET with the change of kinetic energy. This idea is worth taking in because it considers both the crash probability and the crash severity.

Briefly, there are numerous traffic conflict measures which can be divided into five categories. These measures refer to crash probability and crash severity. However, they are not specially designed for e-bikes, so a new measure should be established based on the e-bike driving characteristics.

\section{E-BIKE DRIVING CHARACTERISTICS}

Learning more about the driving characteristics of e-bikes helps to develop the traffic conflict measure. According to the studies based on solid field observations, the main driving characteristics of e-bikes in China are concluded as follows:

Speed characteristics. Due to the absence of strict implementation of e-bike product standards, many e-bikes have a maximum design speed of over $30 \mathrm{~km} / \mathrm{h}$ [1]. Besides, the average operating speed

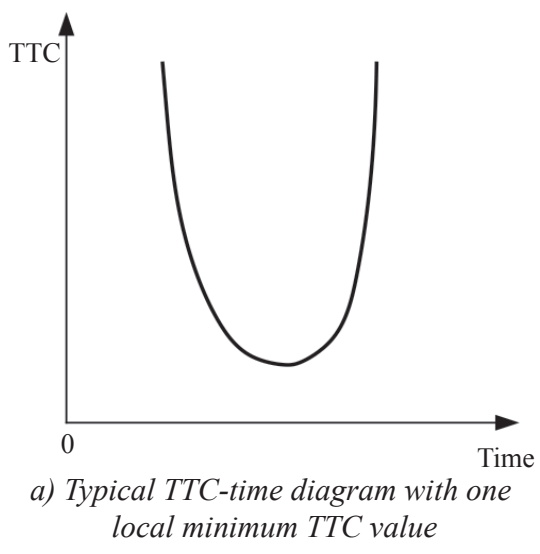

Figure 1-TTC-time diagram of a conflict process of e-bikes is $15-25 \mathrm{~km} / \mathrm{h}$ [22], much higher than that of conventional bicycles, even close to cars on some city roads. Due to the lack of necessary protection as provided by cars and proper speed limit like conventional bicycles, e-bike riders withstand higher safety risks.

Acceleration characteristics. E-bike acceleration is rapid relative to that of conventional bicycles without electric motors. It is not challenging for e-bikes to accelerate from 0 to $20 \mathrm{~km} / \mathrm{h}$ in $4 \mathrm{~s}$ [23]. Fast speed change makes it difficult to predict e-bike behaviour.

Trajectory characteristics. The turning of e-bikes is flexible, resulting in changeable driving trajectories. If disturbed frequently, the trajectories of e-bikes would be fluctuant.

These driving characteristics distinguish the conflict characteristics of e-bikes from those of the cars.

Car drivers are inclined to brake rather than to turn the steering wheel when facing an emergency, because cars are relatively bulky and the direction adjustment within a short time is not easy. However, e-bikes can be flexibly controlled, so the riders tend to change trajectories as well as speed in traffic conflicts.

As a result, in the conflicts involving e-bikes, the conflict points are changeable as the trajectories change. That is, during a conflict process, the position of the expected crash point is no longer fixed, but changeable with time. Similarly, TTC is time-related in a conflict process. However, there is only one value for PET during a conflict process according to Section 2 of this paper. Therefore, the concept of PET is not applicable in e-bike conflicts, while TTC is still suitable as it describes a state.

Furthermore, the change of TTC over time can be analysed. In a typical conflict process, there should be only one local minimum TTC which represents the absolute minimum TTC (Figure 1a) [9]. While in

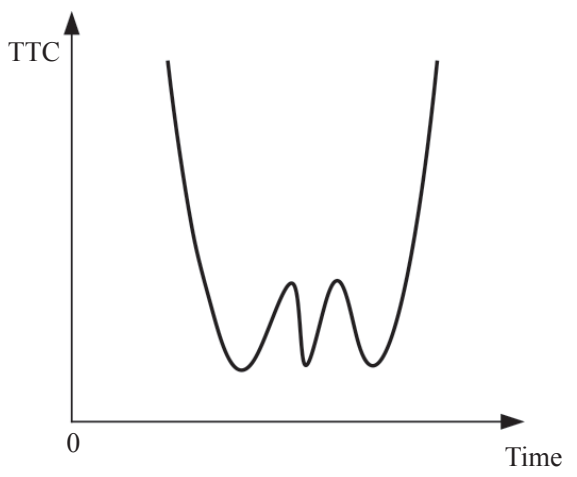

b) TTC-time diagram with several local minimum TTC values involving e-bikes 
the conflict involving e-bikes, it is likely that there is more than one local minimum TTC according to field observation of this study which collected the TTC of e-bike related conflicts from videos taken from intersections in China (Figure 1b). It indicates that because of the driving flexibility and uncertainty of e-bikes, the conflict resolution is probably not a one-time process, but a dynamic process with mutual feedback and continuous adjustment, usually taking more time.

\section{METHODOLOGY}

This study focuses on developing a measure applicable to conflicts involving e-bikes at intersections. The main idea includes three aspects: (1) considering both conflict risk and conflict severity; (2) assessing the entire conflict process in discrete time steps, and "the worst moment" representing this conflict process; (3) considering conflicts between two entities: one is an e-bike, one is another e-bike or other kind of vehicle (usually a car).

The first step in traffic conflict analysis is to identify the traffic conflict. The identification of traffic conflicts is based on the observed evasive actions between two conflict entities, such as braking, swerving, and deceleration [1]. Swerving is frequently used to eliminate danger for e-bikes while deceleration is used for cars.

In order to analyse a conflict process, the start and the end time of the process should be determined. Considering the mixed traffic conditions in China, the TTC of an observed conflict is not high, normally varying between 0.5 and $2.6 \mathrm{~s}$ [1]. Here, a TTC value of $2.6 \mathrm{~s}$ is adopted as the threshold of a conflict process. That is, if TTC drops to less than $2.6 \mathrm{~s}$, the conflict process starts at that time; if TTC rises to higher than $2.6 \mathrm{~s}$, the conflict process ends at that time.

\subsection{Integrated Conflict Intensity (ICI)}

This study defines Integrated Conflict Intensity (ICI) as the measure for traffic conflicts involving e-bikes. In order to make the derivation clearer, Conflict Potential Risk (CPR), Conflict Potential Harm $(\mathrm{CPH})$, and their combination Conflict Potential Risk and Harm (CPRH) are proposed with different meanings.

CPR is proposed to measure the possibility of a conflict converting into a crash (which is called conflict risk here).
As described in Section 3 of this paper, TTC, instead of PET, is used as the crash-estimated time. The smaller the TTC, the higher the conflict risk. However, CPR is supposed to increase as conflict risk grows, so TTC is not directly used.

The form "1/TTC" was considered once. However, when TTC tends to zero, its value tends to infinity, missing the meaning of the measuring possibility. Thus, it is not appropriate here.

Instead, CPR is defined as follows:

$$
C P R=\frac{1}{e^{T T C}}
$$

The value of CPR ranges from 0 to 1 , because TTC $\geq 0$ indicates $e^{T T C} \geq 1$ and $0<\frac{1}{e^{T T C}} \leq 1$. When TTC is large, CPR is close to 0 , suggesting low conflict risk. CPR close to 1 means high conflict risk, and $\mathrm{CPR}=1$ indicates a crash as TTC $=0$. So this form describes the conflict risk reasonably.

Since CPR is connected with TTC, it is a time-related variable like TTC. For every moment in a conflict process, the value of CPR can be calculated.

In addition to $\mathrm{CPR}, \mathrm{CPH}$ is proposed to measure the severity of a possible crash (which is called conflict severity here, since the crash has not actually happened) from the perspective of kinetic energy.

As mentioned in Section 2 of this paper, some research formed physical equations to depict possible kinetic changes of vehicles after crash. However, this method is based on the analysis of scenes that have not actually happened, accompanied with many unverifiable assumptions. In this study, the conflict severity is considered based on reality.

For convenience, the two conflict entities are marked as A and B. For a moment during the conflict process, A and $\mathrm{B}$ run at speeds $v_{a}$ and $v_{b}$, respectively. Now, connect with a line between A and $\mathrm{B}$, and establish a rectangular coordinate system in which $\mathrm{X}$-axis is parallel to the line (Figure 2). Mark the angle between $v_{a}$ (or $v_{b}$ ) and the positive direction of X-axis as $\alpha$ (or $\beta)$. The value of $\alpha$ (or $\beta)$ ranges from 0 to $2 \pi$.

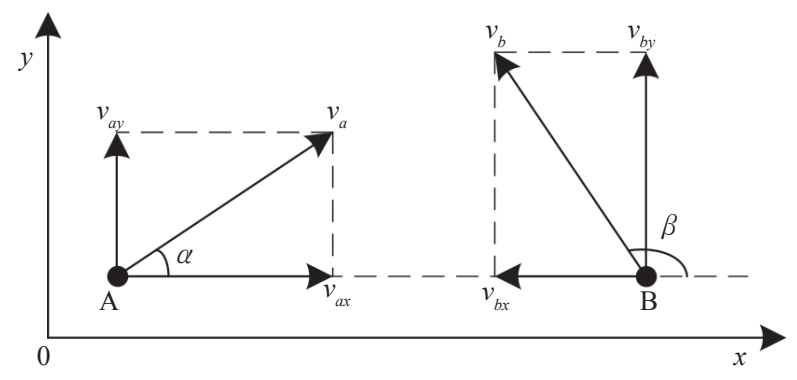

Figure 2 - Diagram for analysis of vehicle speeds 
According to $\alpha$ (or $\beta$ ), $v_{a}$ (or $v_{b}$ ) can be decomposed into $v_{a x}$ and $v_{a v}$ (or $v_{b x}$ and $v_{b y}$ ) along the directions of $\mathrm{X}$-axis and $\mathrm{Y}$-axis. There is no conflict between $v_{a y}$ and $v_{b y}$ because they are parallel to each other. The conflict exists between $v_{a x}$ and $v_{b x}$.

Here, $\Delta v$ is defined as the "relative speed" between A and B. The term "relative speed" implies the speed difference along the direction of $\mathrm{A}$ and $\mathrm{B}$, i.e. the difference between $v_{a x}$ and $v_{b x}$. It is calculated as follows:

$\Delta v=\left|v_{a x}-v_{b x}\right|=\left|v_{a} \cos \alpha-v_{b} \cos \beta\right|$

Although the decomposition analysis of $v_{a}$ and $v_{b}$ above (Figure 2) is based on the ground frame, relative speed $\Delta v$ is defined from the perspective of $\mathrm{A}$ (or B). In A's view, B is coming at a speed of $\Delta v$, and in B's view, A is coming at a speed of $\Delta v$.

Then, $\Delta K_{a}$ and $\Delta K_{b}$ are defined as the "relative kinetic energy":

$\Delta K_{a}=\frac{1}{2} m_{a}(\Delta v)^{2}, \quad K_{b}=\frac{1}{2} m_{b}(\Delta v)^{2}$

where $m_{a}$ and $m_{b}$ are the mass of A and B.

In the perspective of $\mathrm{A}, \mathrm{B}$ is coming towards A with the relative kinetic energy of $\Delta K_{b}$. And in the perspective of $\mathrm{B}, \mathrm{A}$ is coming towards $\mathrm{B}$ with the relative kinetic energy of $\Delta K_{a}$. For $\mathrm{A}$, the larger $\Delta K_{b}$ (i.e. larger $m_{b}$ and $\Delta v$ ), the more harm A would suffer once the crash happens; similarly for B. So $\Delta K_{a}$ and $\Delta K_{b}$ can be used to measure the conflict severity.

To consider $\Delta K_{a}$ and $\Delta K_{b}$ together, their geometric mean can be simply taken as the final definition of CPH. Here, the coefficient " $1 / 2$ " in $\Delta K_{a}$ and $\Delta K_{b}$ is omitted for a simple form.

$C P H=\sqrt{m_{a}(\Delta v)^{2} \cdot m_{b}(\Delta v)^{2}}=\sqrt{m_{a} m_{b}}(\Delta v)^{2}$

Clearly, a larger CPH indicates a higher degree of conflict severity. Similar to CPR, CPH is a time-related variable as $\Delta v$ changes over time.

In order to consider $\mathrm{CPR}$ and $\mathrm{CPH}$ together, $\mathrm{CPRH}$ is defined as follows:

$C P R H=C P R \cdot C P H=\frac{\sqrt{m_{a} m_{b}}(\Delta v)^{2}}{e^{T T C}}$

$\mathrm{CPRH}$ indicates the integrated meaning of CPR and $\mathrm{CPH}$. If the possibility of a potential crash is high, but its severity is slight, CPRH will not be large. Likewise, if a potential crash is estimated to be severe, but its possibility is negligible, $\mathrm{CPRH}$ will not be large either. A rather large CPRH indicates both high conflict risk and high degree of conflict severity.
In fact, indicator CPRH is well adapted for conflicts involving e-bikes. E-bikes run flexibly, often leading to low TTCs. Although CPR is large, it does not mean the situation is critical. In most cases, even if there is an accident, the severity is slight, such as lateral scratching. So CPRH will not be too large as $\mathrm{CPH}$ is small, which is expected in this study.

$\mathrm{CPRH}$ is a variable related to time since $\mathrm{CPR}$ or $\mathrm{CPH}$ are. It is a measure for the conflict state at a certain moment.

Now, an entire conflict process can be studied. In order to assess a conflict process, the moments in the process are selected with a fixed time step $(0.1 \mathrm{~s}$ in this study), and the corresponding CPRHs are calculated for these moments. Suppose there are $n$ moments selected, and the CPRH at moment $i$ is expressed as:

$C P R H_{i}=\sqrt{m_{a} m_{b}} \frac{\left(\Delta v_{i}\right)^{2}}{e^{T T C_{i}}}, \quad i=1, \ldots, n$

where $\Delta v_{i}$ is $\Delta v$ at moment $i$, and $\mathrm{TTC}_{i}$ is TTC at moment $i$.

The largest one among these CPRHs represents the worst moment of this conflict, which is critical for measuring the safety. It is defined as the final measure of a conflict involving e-bikes, called ICI here:

$I C I=\max \left\{C P R H_{i}\right\}_{i=1}^{n}=\sqrt{m_{a} m_{b}} \cdot \max \left\{\frac{\left(\Delta v_{i}\right)^{2}}{e^{T T C_{i}}}\right\}_{i=1}^{n}$

where $\max \left\{\frac{\left(\Delta v_{i}\right)^{2}}{e^{T T C i}}\right\}_{i=1}^{n}$ means the maximum value of all numbers in the set $\left\{\frac{\left(\Delta v_{i}\right)^{2}}{e^{T T C_{i}}}: i=1, \ldots . n\right\}$.

ICI is used to assess a conflict based on the entire process instead of a single moment. It is determined by the CPRH of the worst moment. A large ICI indicates a conflict that not only lasts long, but also has a high conflict risk and high degree of severity at one time.

In the expression of ICI, $\mathrm{TTC}_{i}$ is the indicator related to conflict risk, while $m_{a}, m_{b}$ and $\Delta v_{i}$ are the indicators related to conflict severity. So the term "intensity" in ICI refers to both conflict risk and conflict severity, together indicating the degree of dangerousness of the conflict.

In one word, ICI is an integrated measure for the degree of dangerousness of a conflict, and it is applicable to traffic conflicts that involve e-bikes.

The procedure of calculating ICI for a conflict is summarized in Figure 3. 


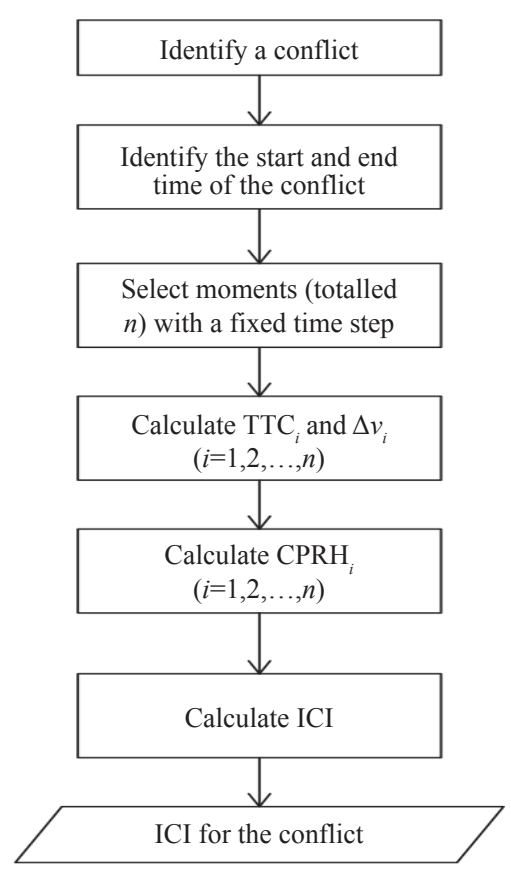

Figure 3 - Flowchart of ICI calculation

\subsection{Threshold determination}

Now, a value of ICI can be calculated, but the value itself has no direct practical meaning. From the value, it is not known to which level the conflict belongs, whether the conflict is serious or not, and to what extent the conflict is serious.

Imitating the severity levels of traffic events proposed by Hydén [24] and Svensson [25], this study divides traffic conflicts into three levels from the perspective of safety: serious conflicts, less serious conflicts, and slight conflicts.

Distinguishing different conflict levels is of great significance since there is no other similar definition of conflict levels related to e-bikes. However, it is not easy to determine the criterion. For one thing, the determination is rather subjective because different people may hold different opinions about the seriousness of the same conflict. For another, criteria for other measures have no reference value because systems are different. For example, many people regard TTC $<1 \mathrm{~s}$ as a serious conflict, but others believe it is $1.5 \mathrm{~s}$ or some other numbers. Even if there is a universally accepted criterion, it cannot be applied here because the factors considered are different. Therefore, it is necessary to know about the traffic safety conditions of e-bikes at intersections as the criterion.
To be as practical as possible here, this study determines the thresholds for the three conflict levels based on the field survey data. One idea is to collect crash data at various intersections, and divide ICI data into three groups as conflict levels according to the severity classification of crash data. This idea is theoretically feasible, but the use of crash data is problematic for its unavailability. Besides, it takes a great deal of time to collect enough samples.

Instead, it is considered to survey subjective safety perceptions of e-bike riders at intersections, and use these data as the criterion to determine the conflict level thresholds. In this study, two types of conflicts are considered: conflicts between two e-bikes, and conflicts between an e-bike and a car.

The questionnaire is designed as shown in Table 1. The questionnaire refers to four choice questions as shown in Table 1, and these questions refer to crashes between two e-bikes (Questions 1, 2 ) and crashes between an e-bike and a car (Questions 3,4), as well as conflict risk (Questions 1, 3) and conflict severity (Questions 2, 4).

For each question in the questionnaire, three options a, b, c are assigned three values $3,2,1$, respectively, indicating the levels of conflict risk or conflict severity. Thus, for each question in each completed questionnaire, there is a corresponding value. In consideration of combining the conflict risk and the conflict severity, the two values for each conflict type are multiplied (i.e. multiply the values of Questions 1 and 2 as the result for conflicts between two e-bikes, and multiply the values of Questions 3 and 4 as the result for conflicts between an e-bike and a car). Obviously, each multiplied value is in the set of $\{9,6,4,3,2,1\}$.

The multiplied value is used to represent the conflict level. In this study, $\{9\}$ is regarded as serious conflicts, $\{6,4\}$ as less serious conflicts, and $\{3,2,1\}$ as slight conflicts. According to this criterion, the values derived from the questionnaire data at one intersection can be divided into three parts, representing three conflict levels. So the proportions of serious conflicts, less serious conflicts and slight conflicts at one intersection can be obtained.

Besides, the ICI data of the observed conflicts at the intersection can be calculated. After being sorted from large to small, these ICI data can be divided according to the proportions of three conflict levels. Then, at the two division positions, two 
Table 1 - Questionnaire about e-bike riders'safety perceptions at intersections

\begin{tabular}{|c|c|}
\hline No. & Questions and options \\
\hline 1 & $\begin{array}{l}\text { Based on this passing experience, do you think that there is a possibility of a crash between two e-bikes at this } \\
\text { intersection? } \\
\text { a. very likely } \\
\text { b. likely } \\
\text { c. not very likely }\end{array}$ \\
\hline 2 & $\begin{array}{l}\text { Based on this passing experience, if there is a crash between two e-bikes at this intersection, what do you think the } \\
\text { crash would be like? } \\
\text { a. a severe crash, causing serious injury or even death } \\
\text { b. a less severe crash, causing persons to fall or be bruised and vehicles to be deformed } \\
\text { c. a minor crash, causing persons to be slightly scratched and vehicles to be slightly damaged at most }\end{array}$ \\
\hline 3 & $\begin{array}{l}\text { Based on this passing experience, do you think that there is a possibility of crash between an e-bike and a car at this } \\
\text { intersection? } \\
\text { a. very likely } \\
\text { b. likely } \\
\text { c. not very likely }\end{array}$ \\
\hline 4 & $\begin{array}{l}\text { Based on this passing experience, if there is a crash between an e-bike and a car at this intersection, what do you think } \\
\text { the crash would be like? } \\
\text { a. a severe crash, causing serious injury or even death } \\
\text { b. a less severe crash, causing persons to fall or get bruised and vehicles to be deformed } \\
\text { c. a minor crash, causing persons to be slightly scratched and vehicles to be slightly damaged at most }\end{array}$ \\
\hline
\end{tabular}

thresholds can be determined: one is the minimum value of serious conflicts (also the maximum value of less serious conflicts), and one is the minimum value of the less serious conflicts (also the maximum value of slight conflicts).

In short, traffic conflicts involving e-bikes are divided into three levels, and the safety perceptions of e-bike riders are regarded as the criterion for threshold determination.

\section{APPLICATION AND VERIFICATION}

In order to get the specific values of thresholds and to verify the proposed measure, field surveys were conducted at intersections, and ICI data were obtained and analysed as well as the questionnaire data.

\subsection{ICI data}

Three four-arm signalized intersections (Table 2) were selected for investigation in Shanghai, China. They vary from each other in signal phases, scales, locations, etc.; thus the safety conditions for e-bikes are very likely to be different, which is necessary for testing the applicability of the proposed measure.
In order to collect ICI data, videos were recorded at the three intersections during rush hours (04:3006:30 p.m.). The movement of vehicles in the videos was analysed by the software George 2.1 (Figure 4). Based on the videos, conflicts were identified and extracted by certain means, i.e. recording the first appeared conflict in every two minutes, which could avoid the subjectivity of artificial choice, so the conflict samples could represent the overall situation. Two types of conflicts (conflicts between two e-bikes, and conflicts between an e-bike and a car) were recorded and analysed separately.

Fifty conflicts were recorded for every type, every intersection, and the corresponding ICIs were calculated with the method described previously. In the calculation, the mass of vehicles (including riders or drivers) was estimated according to the size, the time step was $0.1 \mathrm{~s}$, and other parameters were calculated as described. The International System of Units of Measurement was adopted as the units of these parameters, i.e. $\mathrm{TTC}_{i}[\mathrm{~s}], m_{a}$ and $m_{b}[\mathrm{~kg}]$, $\Delta v_{i}[\mathrm{~m} / \mathrm{s}]$.

The values of those ICIs are shown as boxplots in Figure 5 (a few extremely large values are omitted). For conflicts between two e-bikes, most

Table 2 - Information of the investigated intersections

\begin{tabular}{||c|c|c|c|c||}
\hline \hline ID & Name & Number of Phases & Scale & Location \\
\hline \hline A & Jianhe-Xianxiaxi & 2 & small, subarterial-subarterial & city subcentre \\
\hline B & Changji-Moyu & 3 & medium, subarterial-subarterial & suburb \\
\hline C & Siping-Dalian & 4 & large, arterial-arterial & city centre \\
\hline
\end{tabular}




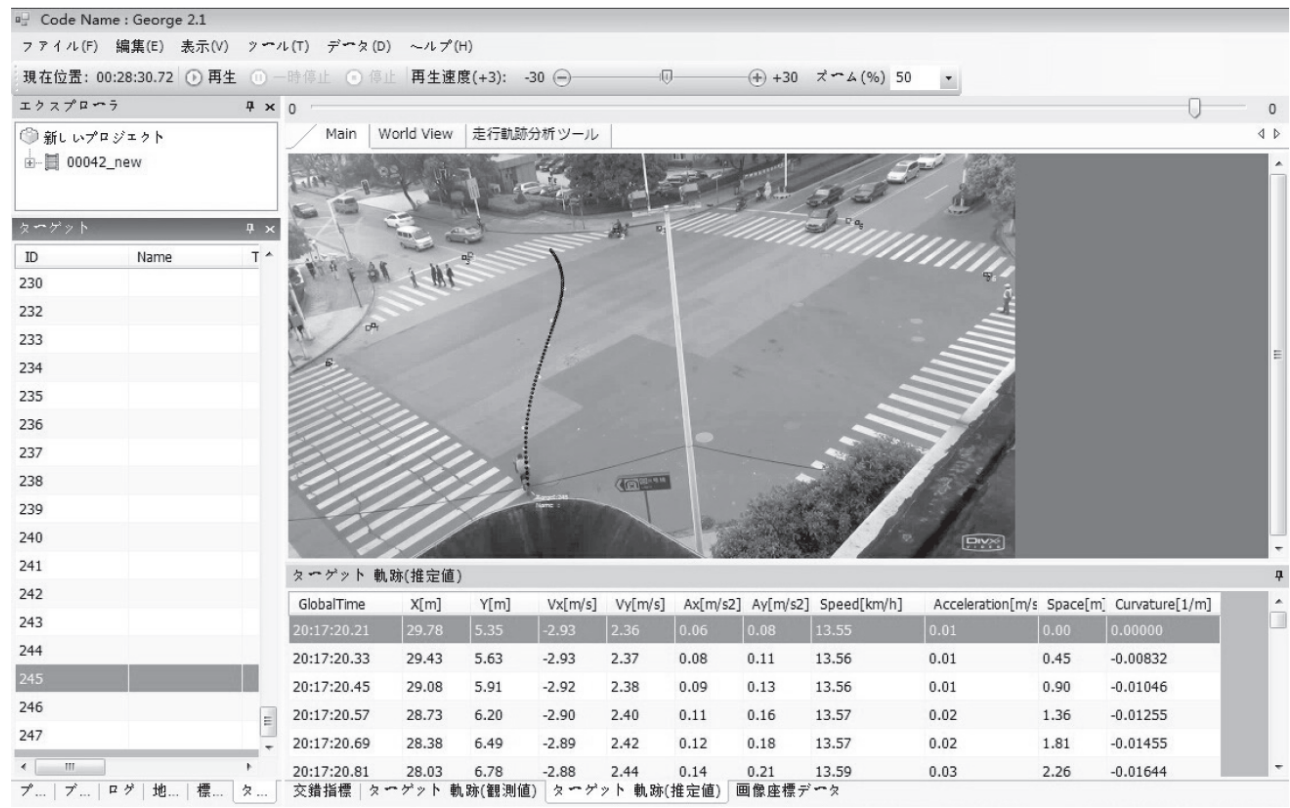

Figure 4-Movement of vehicles analysed by George 2.1

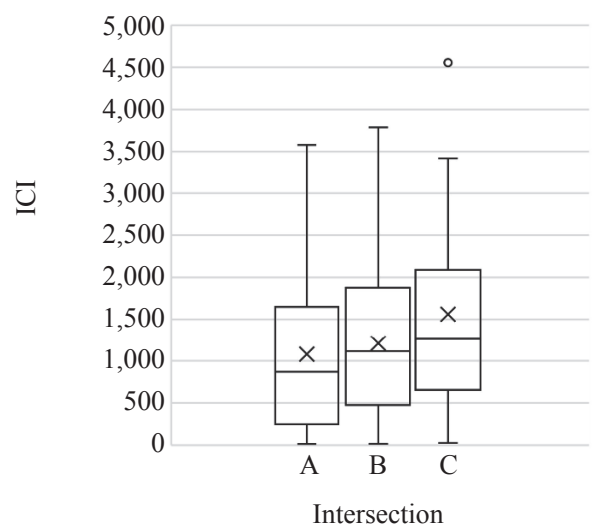

a) Conflicts between two e-bikes

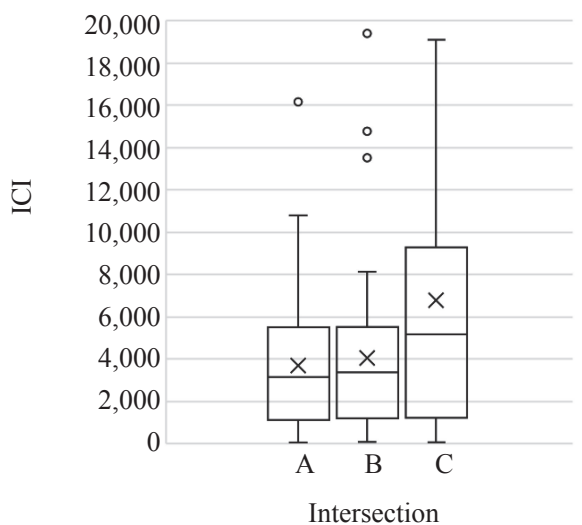

b) Conflicts between an e-bike and a car

Figure 5 - ICI boxplot of two conflict types

(98.7\%) ICI data vary from 0 to 5,000; for conflicts between an e-bike and a car, most (98.7\%) ICI data vary from 0 to 20,000. Non-typical ICI values are some extremely large values, which indicates the conflict is so serious that it almost causes a crash.

To make the interpretation of ICI more intuitive, ICI data were converted into an index called ICI-index, which ranges in a fixed interval $[0,1]$. For conflicts between two e-bikes, the conversion is:

$$
I C I-\text { index }_{1}=\left\{\begin{array}{lc}
\frac{I C I}{5000}, & 0 \leq I C I \leq 5000 \\
1, & I C I>5000
\end{array}\right.
$$

For conflicts between an e-bike and a car, the conversion is:

$I C I-$ index $_{2}= \begin{cases}\frac{I C I}{20000}, & 0 \leq I C I \leq 20000 \\ 1, & I C I>20000\end{cases}$
A larger ICI-index indicates a more serious conflict. ICI-index $=0$ means no conflict, while ICI-index $=1$ means an extremely serious conflict. ICI-index is more convenient to imply the seriousness of a conflict, and it is used for the later analysis.

\subsection{Questionnaire data}

To know the safety conditions of intersections as reference, questionnaire surveys were conducted at the three intersections, that is, for e-bike riders about their subjective safety perceptions of the specific intersection they passed through.

For the sake of safety, the questionnaires were not filled in the field but through Internet. The research team handed out papers, and the questionnaire link was on the papers. This work was implemented at 
Wu Z, Zeng X, Wang L. A New Traffic Conflict Measure for Electric Bicycles at Intersections

Table 3 - Proportions of three conflict levels based on questionnaire data

\begin{tabular}{||l|c|c|c|c|c|c||}
\hline \multirow{2}{*}{\multicolumn{1}{c|}{ Conflict levels }} & \multicolumn{3}{c|}{ Conflicts between two e-bikes } & \multicolumn{3}{c||}{ Conflicts between an e-bike and a car } \\
\cline { 2 - 8 } & A & B & C & A & B & C \\
\hline \hline Serious conflicts & 0.061 & 0.024 & 0.063 & 0.091 & 0.095 & 0.375 \\
\hline Less serious conflicts & 0.394 & 0.524 & 0.583 & 0.636 & 0.667 & 0.354 \\
\hline Slight conflicts & 0.545 & 0.452 & 0.354 & 0.273 & 0.238 & 0.271 \\
\hline
\end{tabular}

the three intersections respectively, on the same day of the week and at the same hours when the videos were recorded. In total, 250 papers were handed out at each intersection, and 33, 42, 48 valid questionnaires were collected for Intersections A, B, C, respectively. The collection rate was not high maybe because many riders just forgot the papers. But the samples were basically sufficient like some other studies (e.g. the study by Lowry et al. [26]: 92 participants, and the study by Wang et al. [27]: 72 participants).

The proportions of three conflict levels at each intersection based on the questionnaire data are shown in Table 3.

\subsection{Thresholds and verification}

With the proportions derived from questionnaire data, the ICI data were divided, and the thresholds determined at the division positions. Table 4 shows the two thresholds derived from each intersection: one is the minimum value of serious conflicts, and one is the minimum value of less serious conflicts. Figure 6 compares the conflict level ranges of different intersections for each conflict type.

The thresholds for serious conflicts derived from different intersections are close to each other, and so are the thresholds for less serious conflicts. To quantify the differences, the Coefficient of Variation is calculated in Table 5 .

In the four cases, the Coefficient of Variation of the threshold is no more than 0.08 . It indicates that the threshold deviation does not exceed $8 \%$. Therefore, although the three intersections are different in many aspects, their ICI-index thresholds are similar to each other. In order to finally determine the thresholds, the values in Table 6 are taken as the unified ICI-index thresholds.

The invariance of thresholds derived from different intersections indicates that the ICI-index thresholds are independent of the intersections. It is verified that ICI and its thresholds are applicable for different scales of four-arm signalized intersections.

Table 4-ICI-index thresholds for conflict levels derived from each intersection

\begin{tabular}{||l|c|c|c|c|c|c||}
\hline \multirow{2}{*}{ Conflict levels } & \multicolumn{3}{c|}{ Conflicts between two e-bikes } & \multicolumn{3}{c||}{ Conflicts between an e-bike and a car } \\
\cline { 2 - 8 } & A & B & C & A & B & C \\
\hline \hline Serious conflicts & 0.64 & 0.64 & 0.69 & 0.37 & 0.38 & 0.34 \\
\hline Less serious conflicts & 0.17 & 0.19 & 0.18 & 0.06 & 0.06 & 0.07 \\
\hline
\end{tabular}

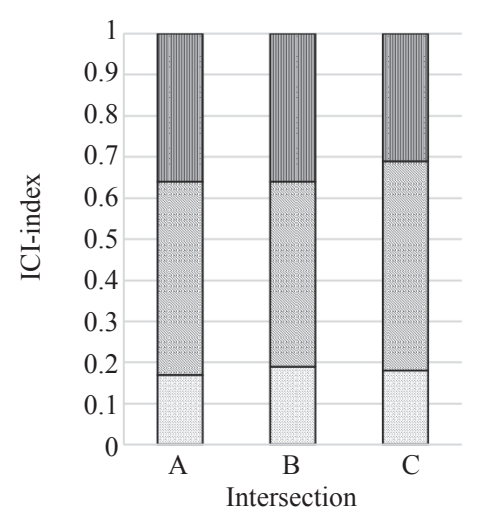

a) Conflicts between two e-bikes

m Serious conflicts $\square$ Less serious conflicts

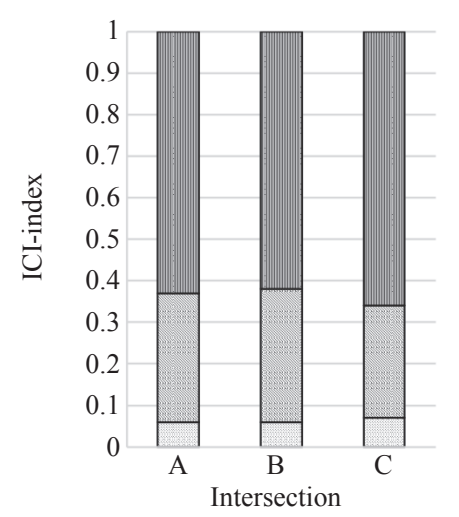

b) Conflicts between an e-bike and a car

$\square$ Slight conflicts

Figure 6-ICI-index ranges of three conflict levels for two conflict types 
Wu Z, Zeng X, Wang L. A New Traffic Conflict Measure for Electric Bicycles at Intersections

Table 5 - Threshold statistics of the three intersections

\begin{tabular}{||l|c|c|c|c||}
\hline \multirow{2}{*}{\multicolumn{1}{|c|}{ Statistics }} & \multicolumn{2}{|c|}{ Conflicts between two e-bikes } & \multicolumn{2}{c|}{ Conflicts between an e-bike and a car } \\
\cline { 2 - 5 } & $\begin{array}{c}\text { Threshold for serious } \\
\text { conflicts }\end{array}$ & $\begin{array}{c}\text { Threshold for less } \\
\text { serious conflicts }\end{array}$ & $\begin{array}{c}\text { Threshold for serious } \\
\text { conflicts }\end{array}$ & $\begin{array}{c}\text { Threshold for less } \\
\text { serious conflicts }\end{array}$ \\
\hline \hline Mean & 0.657 & 0.180 & 0.363 & 0.0633 \\
\hline Standard deviation & 0.0236 & 0.00816 & 0.0170 & 0.00471 \\
\hline Coefficient of Variation & 0.0359 & 0.0454 & 0.0468 & 0.0744 \\
\hline
\end{tabular}

Table 6 - Unified ICI-index thresholds and ranges for conflict levels

\begin{tabular}{||l|c|c|c|c||}
\hline \multirow{2}{*}{\multicolumn{1}{|c|}{ Conflict levels }} & \multicolumn{2}{c|}{ Conflicts between two e-bikes } & \multicolumn{2}{c|}{ Conflicts between an e-bike and a car } \\
\cline { 2 - 5 } & Threshold & Range & Threshold & Range \\
\hline \hline Serious conflicts & 0.66 & $(0.66,1]$ & 0.36 & $(0.36,1]$ \\
\hline Less serious conflicts & 0.18 & $(0.18,0.66]$ & 0.06 & $(0.06,0.36]$ \\
\hline Slight conflicts & $/$ & {$[0,0.18]$} & $/$ & {$[0,0.06]$} \\
\hline
\end{tabular}

Besides, if considering the threshold determination process conversely, the proportions of three conflict levels can be derived from ICI data with the unified thresholds, and they are the same as the proportions derived from the questionnaire data. This indicates that the measure of ICI data for conflict levels is in accordance with that of questionnaire data (which is regarded as the criterion). So it can be concluded that ICI and its thresholds for determining conflict levels are valid and practical.

\section{CONCLUSION}

Although there are numerous conflict measures or indicators, they are not specially designed for e-bikes, thus needing improvement. The analysis of driving characteristics of e-bikes reveals that they differ from cars greatly. E-bikes have high flexibility to change speed and trajectories, leading to a changeable conflict point, more uncertainty, and more time for conflict resolution. Thus, this study focuses on a new measure for traffic conflicts involving e-bikes at intersections.

The traffic conflict measure for e-bikes is established based on the considerations of both conflict risk and conflict severity. CPR is proposed to measure the possibility of a conflict converting into a crash with TTC, and $\mathrm{CPH}$ is proposed to measure the severity degree of a possible crash with relative kinetic energy. The combination of $\mathrm{CPR}$ and $\mathrm{CPH}$ is $\mathrm{CPRH}$, which measures the conflict at a moment. The maximum $\mathrm{CPRH}$ during a complete conflict process is defined as ICI, which is finally used to measure conflicts involving e-bikes.
The method of determining ICI thresholds for three conflict levels (serious, less serious and slight), and two conflict types (conflicts between two e-bikes, and conflicts between an e-bike and a car) is put forward based on the questionnaire data about safety perceptions of e-bike riders, which is regarded as the criterion of e-bike safety conditions at intersections.

Field surveys at four-arm signalized intersections about conflicts involving e-bikes were conducted to determine ICI thresholds and to verify them. ICI was converted into ICI-index ranging in $[0,1]$ to make its meaning more intuitive. The thresholds at three intersections were calculated, and they are close to each other, which indicates that the ICI-index thresholds are independent of intersections. It is verified that the measure of ICI data for conflict levels is in accordance with that of the questionnaire data, so ICI and its thresholds meet the criterion of e-bike safety conditions at intersections.

This work can be used in the selection of intersections to be improved for e-bikes. A larger proportion of serious conflicts suggests that there is greater need to take improvement measures at this intersection. The improvement can be specific to the conflict type.

Future work can aim at increasing the amount of intersections to further verify the thresholds proposed by this study. Moreover, it can be tested whether this measure can be used for different geometries of intersections in different countries.

\section{ACKNOWLEDGEMENT}

The research was supported by the National Natural Science Foundation of China (No. 61773288) and the National Key Research and Development Program of China (No. 2018YFB1600805). 
吴志周, 博士 ${ }^{1}$

电子邮箱: wuzhizhou@tongji.edu.cn

曾昕, 硕士研究生 ${ }^{1}$

电子邮箱: zengxin13579@qq.com

王玲, 博士 ${ }^{1}$ (通讯作者)

电子邮箱: wang ling@tongji.edu.cn

1 同济大学道路与交通工程教育部重点实验室

中国上海市嘉定区曹安公路4800号

\section{面向电动自行车的交叉口交通冲突评价指标}

摘要

随着电动自行车在中国的流行，其安全状况日益 受到关注。交通冲突技术是交通安全分析中常用的 方法, 面向汽车提出了许多冲突评价指标。然而, 电动自行车在速度和轨迹变化上具有很高的灵活 性, 这与汽车不同, 因此, 有必要单独面向电动自 行车研究冲突评价指标。本文基于电动自行车的驾 驶特性, 提出了一种针对交叉口电动自行车交通冲 突的评价指标一一综合冲突强度。它用于衡量冲突 过程的危险程度，既考虑了冲突风险又考虑了冲突 严重程度。碰撞时间用于衡量冲突风险; 相对动能 用于衡量冲突严重程度。综合冲突强度可以通过视 频分析来计算。本文将电动自行车骑行者安全感受 的调查问卷结果作为交叉口电动自行车安全状况的 评价标准，并基于该标准，提出了面向三种冲突水 平 (严重冲突、一般冲突、轻微冲突) 和两种冲突 类型 (电动自行车与电动自行车冲突、电动自行车 与汽车冲突）的综合冲突强度阈值确定方法。本文 对三个实际交叉口的电动自行车冲突状况开展了视 频录制与问卷调查，确定了适用于不同交叉口的统 一阈值, 验证了综合冲突强度及其阈值符合电动自 行车安全状况的标准。这项研究可用于篮选急需改 善电动自行车交通安全的交叉口。

\section{关键词}

电动自行车; 交通冲突; 冲突评价

指标; 碰撞时间; 动能; 阈值

\section{REFERENCES}

[1] Bai L, Liu P, Chen Y, Zhang X, Wang W. Comparative Analysis of the Safety Effects of Electric Bikes at Signalized Intersections. Transportation Research Part D: Transport and Environment. 2013;20: 48-54.

[2] Perkins SR, Harris JL. Traffic Conflict Characteristics: Accident Potential at Intersections. Highway Research Record. 1968;225: 35-43.

[3] Baker WT. An Evaluation of the Traffic Conflicts Technique. The $51^{\text {st }}$ Annual Meeting of the Highway Research Board, 17-21 January 1972, Washington, D.C.; 1972.

[4] Lin S, He M, Tan Y, He M. Comparison Study on Operating Speeds of Electric Bicycles and Bicycles: Experience from Field Investigation in Kunming, China. Transportation Research Record: Journal of the Transportation Research Board. 2008;2048: 52-59.

[5] Schepers JP, Fishman E, Hertog PD, Wolt KK, Schwab AL. The Safety of Electrically Assisted Bicycles
Compared to Classic Bicycles. Accident Analysis \& Prevention. 2014;73: 174-180.

[6] Gorenflo C, Rios I, Golab L, Keshav S. Usage Patterns of Electric Bicycles: An Analysis of the WeBike Project. Journal of Advanced Transportation. 2017; Article ID 3739505 .

[7] Hertach P, Uhr A, Niemann S, Cavegn M. Characteristics of Single-vehicle Crashes with E-bikes in Switzerland. Accident Analysis \& Prevention. 2018;117: 232-238.

[8] Bai L, Liu P, Wang W, Chen Y. Characteristics of Traffic Conflicts between Electric Bicycles and Motor Vehicles at Unsignalized Intersections. The $12^{\text {th }}$ COTA International Conference of Transportation Professionals, 3-6 August 2012, Beijing, China; 2012.

[9] Hayward JC. Near-Miss Determination through Use of a Scale of Danger. Highway Research Board. 1972;384: 24-34.

[10] Hydén C, Linderholm L. The Swedish Traffic-Conflicts Technique. In: Asmussen E. (ed.) International Calibration Study of Traffic Conflict Techniques. Berlin, Heidelberg: Springer; 1984. p. 133-139.

[11] Hirst S, Graham R. The Format and Presentation of Collision Warnings. In: Ergonomics and safety of intelligent driver interfaces. Mahwah, USA: Lawrence Erlbaum Associates; 1997. p. 203-219.

[12] Allen BL, Shin BT, Cooper P. Analysis of Traffic Conflicts and Collisions. Transportation Research Record: Journal of the Transportation Research Board. 1978;667: 67-74.

[13] Hydén C. A Traffic-Conflicts Technique for Determining Risk. Bulletin 15B. Lund, Sweden: Department of Traffic Planning and Engineering, Lund Institute of Technology; 1977.

[14] Minderhoud M, Bovy PH. Extended Time-to-collision Measures for Road Traffic Safety Assessment. Accident Analysis \& Prevention. 2001;33: 89-97.

[15] Chen P, Zeng W, Yu G, Wang Y. Surrogate Safety Analysis of Pedestrian-Vehicle Conflict at Intersections Using Unmanned Aerial Vehicle Videos. Journal of Advanced Transportation. 2017; Article ID 5202150.

[16] Kloeden C, Ponte G, Mclean J. Travelling Speed and the Risk of Crash Involvement: The South Australian Experience. National Speed and Road Safety Conference, 2324 August 2001, Adelaide, Australia; 2001.

[17] Shelby SG. Delta-V as a Measure of Traffic Conflict Severity. The $3^{\text {rd }}$ International Conference on Road Safety and Simulation, 14-16 September 2011, Indianapolis, USA; 2011.

[18] Chen Y, Liu P, Wang W. Using Kinetic Energy to Evaluate the Severity of Different Types of Traffic Conflict at Signalized Intersections. The $11^{\text {th }}$ International Conference of Chinese Transportation Professionals, 14-17 August 2011, Nanjing, China; 2011.

[19] Sobhani A, Young W, Logan D, Bahrololoom S. A Kinetic Energy Model of Two-Vehicle Crash Injury Severity. Accident Analysis \& Prevention. 2011;43(3): 741-754.

[20] Fazekas A, Hennecke F, Kalló E, Oeser M. A Novel Surrogate Safety Indicator Based on Constant Initial Acceleration and Reaction Time Assumption. Journal of Advanced Transportation. 2017; Article ID 8376572.

[21] Alhajyaseen WKM. The Development of Conflict Index 
for the Safety Assessment of Intersections Considering Crash Probability and Severity. Procedia Computer Science. 2014;32: 364-371.

[22] Chen J, Xie Z, Qian C. Traffic Conflict Models on Shared-Use Paths Used by Pedestrians, Cyclists, and Electric Bicycle Riders. The $10^{\text {th }}$ International Conference of Chinese Transportation Professionals, 4-8 August 2010, Beijing, China; 2010.

[23] Dong B-J. The Study of Characteristics of Electric Bicycle. Master's thesis. Tongji University, Shanghai; 2008.

[24] Hydén C. The Development of a Method for Traffic Safety Evaluation: the Swedish Traffic Conflicts Technique. Bulletin 70. Lund, Sweden: Department of Traffic Planning and Engineering, Lund Institute of Technology; 1987.

[25] Svensson A. A Method for Analysing the Traffic Process in a Safety Perspective. Bulletin 166. Lund, Sweden: Department of Traffic Planning and Engineering, Lund Institute of Technology; 1998.

[26] Lowry M, McGrath R, Scruggs P, Paul D. Practitioner Survey and Measurement Error in Manual Bicycle and Pedestrian Count Programs. International Journal of Sustainable Transportation. 2016;10(8): 720-729.

[27] Wang Y, Xing F, Zhang L. Research on the Vehicle-Bicycle Conflict Model at Signalized Intersection. International Conference on Green Intelligent Transportation System and Safety, 1-4 July 2016, Nanjing, China; 2016. 